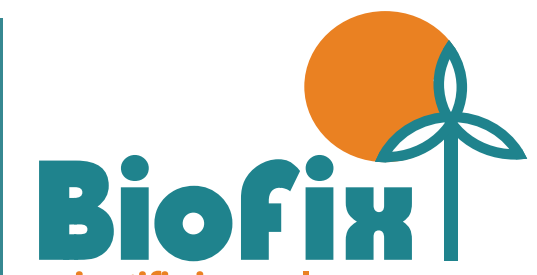

scientific journal

v. 2 n. 22017

Recebido em 19/09/2017

Aceito em 28/11/2017

Publicado em 29/11/2017

DOI: dx.doi.org/10.5380/biofix.v2i2.55311

\title{
INCIDÊNCIA DE INSETOS-PRAGA EM SISTEMA AGROFLORESTAL MULTIESTRATA NA REGIÃO CENTRO-SUL DO PARANÁ
}

INCIDENCE OF INSECTS-PRAGUE IN A MULTIFASTATIC AGROFORESTRY SYSTEM IN THE CENTRAL-SOUTH REGION OF PARANÁ

\author{
Thiare Aparecida do Valle Coelho ${ }^{1}$ \\ Daniele Ukan ${ }^{2}$ \\ Gabriela Schmitz Gomes ${ }^{3}$ \\ Izabela Moura Duin ${ }^{4}$
}

Universidade Federal do Paraná, Curitiba, Paraná, Brasil coelho.thiare@gmail.com ${ }^{1}$ \& izabeladuin@hotmail.com ${ }^{4}$

Universidade Estadual do Centro-Oeste, Irati, Paraná, Brasil daniukan@yahoo.com.br $r^{2}$ \& profagabrielaflorestal@yahoo.com.br ${ }^{3}$

\section{RESUMO}

O presente trabalho tem como objetivo identificar e quantificar a incidência de insetos-praga em sistemas agroflorestais, avaliando o grau de danos causados e testando a composição dos sistemas no sentido de minimizar a ocorrência. Os sistemas agroflorestais foram compostos em ninhos, utilizando seis espécies arbóreas: aroeira-pimenteira (Schinus terebinthifolius Raddi), erva-mate (Ilex paraguariensis A. St.-Hil), araçá (Psidium cattleyanum Sabine), pitanga (Eugenia uniflora L.), guabiroba (Campomanesia xanthocarpa (Mart.) O.Berg) e cerejeira (Eugenia involucrata DC.). Assim, foi utilizado o delineamento inteiramente casualizado com quatro tratamentos e oito repetições. Durante noventa dias, foram realizadas sete avaliações, percorrendo todos os ninhos e verificando a presença de insetos nos períodos da manhã e da tarde, para posterior identificação. Foi utilizado o software Assistat para a realização da análise de variância e teste de Tukey para comparação das médias, ao nível de $5 \%$ de significância. A erva-mate foi a espécie que apresentou maior incidência de insetos, sendo a que teve mais indivíduos mortos. A melhor composição para os ninhos, com relação a incidência de insetos, foi aroeira-pimenteira, erva-mate e araçá.

PALAVRAS-CHAVE: Agrofloresta, Ilex paraguariensis, Schinus terebinthifolius.

\section{ABSTRACT}

This paper aims to identify and quantify the incidence of insect pests in agroforestry systems, evaluating the degree of caused damage and testing the composition of the systems to minimize the occurrence. Agroforestry systems were composed in nests, using six tree species: aroeira-pimenteira (Schinus terebinthifolius Raddi), erva-mate (Ilex paraguariensis A. St.-Hil), araçá (Psidium cattleyanum Sabine), pitanga (Eugenia uniflora L.), guabiroba (Campomanesia xanthocarpa (Mart.) O.Berg), and cerejeira (Eugenia involucrata DC). Thus, a completely randomized design with four treatments and eight replications was used. For 90 days, seven evaluations were carried out, traversing all nests and verifying the presence of insects in the morning and afternoon, for posteriorly identification. The Assistat software was used to perform the analysis of variance and Tukey's test for comparison of means at the $5 \%$ level of significance. The erva-mate was the species that presented the highest incidence of insects, being the one that had more individuals dead. The best composition for the nests, in relationship to the incidence of insects, was aroeira-pimenteira, erva-mate, and araçá.

KEYWORDS: Agroforestry, Ilex paraguariensis, Schinus terebinthifolius. 


\section{INTRODUÇÃO}

A região Centro-Sul do estado do Paraná teve seu desenvolvimento vinculado as atividades econômicas associadas à exploração de recursos da natureza, as quais ocorreram de forma predatória e rudimentar, como a exploração da erva-mate e da madeira. Seu território está, em grande parte, na região denominada Paraná Tradicional, cujo desenvolvimento econômico foi baseado em grandes propriedades rurais de agricultura de subsistência, com a utilização de mão-de-obra escrava e trabalho familiar.

Desta forma, devido aos grandes latifúndios, os pequenos agricultores tiveram sua produção limitada e, com isso, precisaram utilizar diferentes técnicas para seu sustento. Estando inseridos na região de Floresta Ombrófila Mista, muitos não haviam notado os diferentes usos que a floresta lhes proporciona, muitas vezes explorando-a de forma irregular. Dessa forma, é necessário buscar alternativas para recuperação, enriquecimento e manejo sustentável dessas áreas.

Uma das maneiras de se obter esse enriquecimento para pequenos produtores é por meio da implantação de sistemas agroflorestais (SAFs), onde são consorciadas espécies florestais (madeireira, não-madeireira e frutífera) com espécies agrícolas. Além da recuperação de áreas degradadas e do manejo da reserva legal, os SAFs são uma excelente alternativa, pois, ao mesmo tempo em que se conserva ou se recupera as áreas, o produtor se beneficia produzindo alimentos (MARTINOSKI, 2013).

Nesses sistemas, a vegetação não é toda retirada para a plantação de monocultura em larga extensão. Para o bom funcionamento dos sistemas, é necessário entender o funcionamento da natureza e imitá-la, utilizando as relações entre os seres vivos e conhecendo as características de cada espécie e sua relação com as demais, onde é possível o controle natural das pragas por meio do restabelecimento do equilíbrio ecológico (NARDELE; CONDE, 2008).

Segundo Fernandes (2006), citado por Watanabe et al. (2010), plantando várias espécies, o agricultor reduz os riscos de perdas econômicas, como seria no caso das monoculturas, reduz a incidência de pragas e doenças, obtém rendas provenientes das diferentes culturas e otimiza a utilização da mão-de-obra, fazendo o uso mais intensivo e racional do solo.

A diversificação da vegetação na área cultivada pode diminuir a herbivoria por diversificar recursos, dificultando a localização e a colonização das plantas hospedeiras pelos herbívoros, ou por favorecer os inimigos naturais, considerando a disponibilidade e a abundância de alimentos alternativos, a exemplo de: néctar, pólen e honeydew, ao fornecimento de áreas de refúgio e de microclima e a disponibilidade de presas alternativas. Deve-se enfatizar que nos SAFs, é necessária a diversificação estratégica da vegetação com plantas que tenham características capazes de atrair e manter os inimigos naturais de interesse (REZENDE et al., 2011).

Quando são desenvolvidos estudos de biodiversidade, dentro do enfoque entomológico em SAFs, Arias (1987) relata que há tendência de existir maiores populações de herbívoros quando há a combinação entre quatro plantas perenes e anuais, quando comparadas aos sistemas de cultivos mistos compostos somente de plantas anuais. Assim, pode-se esperar que os níveis de infestação das pragas tendam a ser menores em sistemas agroflorestais sem a presença de culturas anuais (FAZOLIN; SILVA, 1996).

Portanto, este artigo tem como objetivo identificar e quantificar a incidência de insetos-praga nos sistemas agroflorestais, avaliando o grau de danos causados e testando a composição dos sistemas para minimizar a sua ocorrência.

\section{MATERIAL E MÉTODOS}

\section{Localização da área experimental}

O experimento foi realizado entre os meses de dezembro a abril em uma propriedade localizada na comunidade de Rio dos Patos, município de São João do Triunfo - PR, o qual integra a região Centro-Sul do Paraná. O clima é do tipo Cfb - Köppen (IAPAR, 2014), temperado, com verão ameno, chuvas uniformemente distribuídas, sem estação seca definida, temperatura média de $17,4^{\circ} \mathrm{C}$, pluviosidade média anual de $1.451 \mathrm{~mm}$ e ocorrência de geadas severas (EMBRAPA FLORESTAS, 2016).

\section{Delineamento experimental}

O delineamento utilizado no experimento foi o inteiramente casualizado (DIC) com quatro tratamentos e oito repetições (Figura 1), sendo os tratamentos:

- Tratamento 1: sistema agroflorestal composto por: Schinus terebinthifolius Raddi (aroeira-pimenteira), Ilex paraguariensis A. St.-Hil (erva-mate) e Psidium cattleyanum Sabine (araçá);

- Tratamento 2: sistema agroflorestal composto por: aroeira-pimenteira, erva-mate e Eugenia uniflora L. (pitanga); 
- Tratamento 3: sistema agroflorestal composto por: aroeira-pimenteira, erva-mate e Campomaneis xanthocarpa (Mart.) O.Berg (guabiroba); e

- Tratamento 4: sistema agroflorestal composto por: aroeira-pimenteira, erva-mate e Eugenia involucrata DC. (cerejeira).

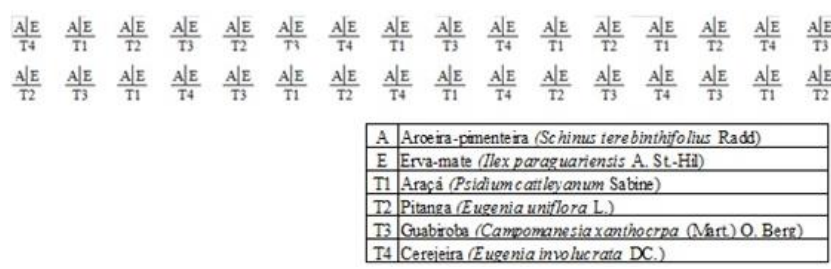

Figura 1. Arranjo espacial do delineamento experimental.

Foi aplicada a análise de variância e o teste de Tukey, para comparação das médias dos tratamentos, ao nível de $5 \%$ de significância.

\section{Implantação dos SAFs}

Os SAFs foram compostos em ninhos (Figura 2), sendo que cada foi composto por uma espécie de rápido crescimento (aroeira-pimenteira); uma de crescimento em densos agrupamentos e que possibilita utilizar as folhas, através da extração de forma manejada (ervamate); e uma frutífera. Foram utilizadas quatro espécies de frutíferas diferentes: araçá, pitanga, guabiroba e cerejeira. Nos ninhos, as mudas permaneceram distantes em 0,4 m umas das outras, com espaçamento de $3 \mathrm{~m} \times 2$ $\mathrm{m}$ entre ninhos.

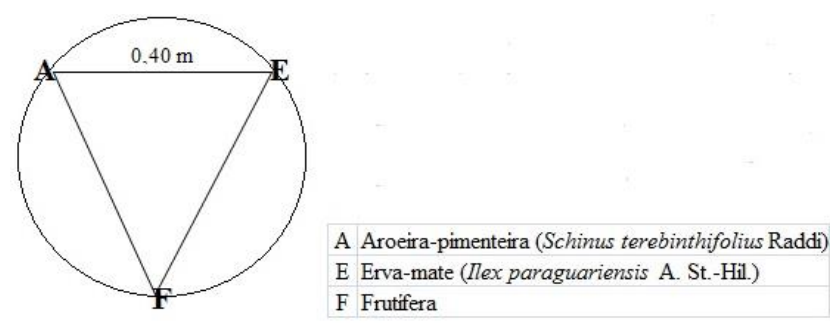

Figura 2. Representação do ninho com a disposição das espécies.

As mudas das frutíferas e da aroeira-pimenteira foram obtidas no Viveiro do Instituto Ambiental do Paraná (IAP), do município de Fernandes Pinheiro - PR, ao passo que as mudas de erva-mate foram obtidas com produtor da localidade de Guaiaca no município de São João do Triunfo - PR. O preparo de solo da área de plantio foi realizado por meio de gradagem realizada algumas semanas antes do plantio.

\section{Avaliações}

As avaliações começaram no primeiro dia após o plantio, sendo realizadas nos períodos da manhã e da tarde ( $8 \mathrm{~h}$ e $17 \mathrm{~h}$, respectivamente). Foram percorridas todas as mudas e verificada a ocorrência de danos de insetos no local. Foram realizadas sete avaliações: 1 dia, 5 dias, 10 dias, 15 dias, 30 dias, 60 dias e 90 dias após o plantio.

Os insetos encontrados foram contados e coletados. Após a coleta, eles foram acondicionados em recipientes com álcool $70 \%$, para posteriormente serem identificados e montados com alfinetes entomológicos no laboratório de Entomologia Florestal do Curso de Engenharia Florestal, da Universidade Estadual do Centro-Oeste.

\section{Identificação dos insetos}

Os insetos coletados foram identificados em nível de família, com auxílio de chave dicotômica proposta por Fujihara et al. (2011). Foram quantificados por meio de contagem dos exemplares e avaliados quanto ao potencial como inseto-praga com auxílio da literatura, onde se obtiveram informações sobre as pragas e culturas atacadas.

\section{RESULTADOS E DISCUSSÃO}

Na primeira avaliação, foi realizada a avaliação visual das mudas. Nesse momento, foram encontrados no local insetos Orthoptera - Gyllidae e Tetrigidae, popularmente conhecidos como grilo-preto e gafanhoto respectivamente.

Além dos insetos, foi verificado que indivíduos de llex paraguariensis (ervas-mate) presentes nos tratamentos T1, T2, T3 e T4 e em suas repetições, exceto T4-R1, apresentaram folhas danificadas. Em T2-R8 e T4-R5, além das folhas de erva-mate apresentarem danos, elas mostraram manchas escuras, bem como encarquilhadas em T4-R5.

Com relação à Schinus terebinthifolius (aroeirapimenteira), também apresentaram folhas danificadas, porém menos repetições apresentaram o dano, sendo o mesmo verificado com maior frequência junto do T3 (R1, $R 3, R 4, R 6, R 7$ e R8), com aparição em T1 (R2, R3, R4 e $R 7), T 2$ (R4 e R8) e T4 (R2, R4 e R7).

Notou-se que T2 e T3 - Eugenia uniflora (pitanga) e Campomanesia xanthocarpa (guabiroba), respectivamente, apresentaram danos em todas as repetições. Os tratamentos T1 e T4 - Psidium cattleyanum 
(araçá) e Eugenia involucrata (cerejeira) apresentaram menos danos, sendo os mesmos encontrados em apenas três repetições (T1- R2, T1-R3, T1-R5; T4-R2, T4-R5 e T4R6). No período da tarde, não foi possível realizar a avaliação devido à ocorrência de chuva.

A segunda avaliação ocorreu 5 dias após o plantio, em que se verificou danos em novas mudas e danos diferentes em mudas que já apresentaram danos. $\mathrm{Na}$ erva-mate, manchas em folhas foram observados nos tratamentos: T1-R6, T2-R8, T3-R4, T3-R6, T3-R8, T4-R6 e T4-R8. Além disso, foram encontradas formigas do gênero Acromyrmex e um exemplar de um inseto pertencente à ordem Diptera da família Culicidae em T2-R8.

$\mathrm{Na}$ aroeira-pimenteira, foram verificados danos nos tratamentos: T1-R5, T2-R3, T2-R5, T2-R7, T4-R6 e T4-R8. No ninho T4-R8, foi encontrado grilo-preto (Orthoptera Gryllidae). No tratamento referente ao araçá, foram encontrados danos em T1-R1, T1-R4, T1-R6 T1-R7 e T1-R8, sendo que manchas pretas nas folhas foram verificadas em T1-R6 e T1-R8.

No segundo tratamento, referente à pitanga, foram verificadas manchas nas folhas de T2-R7 e um inseto da ordem Diptera da família Culicidae. No tratamento de guabiroba, foi encontrado um inseto pertencente da ordem Diptera de família não identificada em T3-R4. Em T4, cerejeira, foram encontrados danos em T4-R1, T4-R7 o qual também apresentava manchas em suas folhas - e T4-R6, onde a ponta das folhas apresentava-se seca.

$\mathrm{Na}$ avaliação referente ao período da tarde, não foi verificada a presença de insetos nos ninhos ou nas mudas. $\mathrm{Na}$ terceira avaliação, folhas manchadas foram encontradas para erva-mate nos tratamentos T1-R3, T1R4, T2-R2, T3-R2 e T4-R5, sendo verificadas folhas encarquilhadas em T2-R5 e T4-R5. Novamente foi encontrada formiga cortadeira do gênero Acromyrmex, no ninho referente à T3-R3.

Nessa avaliação, foi verificado nos tratamentos T2-R1 e T4-R1 a presença de insetos pertencentes à ordem Diptera e a família Tipulidae nos exemplares de ervamate. Ainda foi verificada a presença de gafanhoto (Orthoptera - Tetrigidae) em T2-R1 no exemplar de pitanga. A avaliação no período da tarde ocorreu após um período de chuva e não foi constatada a presença de insetos nos ninhos ou nas mudas.

Na quarta avaliação, foi encontrado em T4-R7 insetos pertencentes à ordem Diptera e a família não identificada na erva-mate. Ainda, foi verificada a primeira ocorrência de mortalidade em T3-R6 no exemplar de erva-mate. No período da tarde, foi encontrado em T2-R5, também na erva-mate, inseto pertencente a ordem Coleoptera e a família Dasytidae (Figura 2).

A quinta avaliação ocorreu 30 dias após o plantio. Nessa avaliação, foi verificada a morte de mais exemplares de erva-mate nos tratamentos T1-R7, T2-R2, T2-R4 e T4-R6. Na avaliação referente ao período da manhã, foi verificada a presença de inseto pertencente a ordem Hymenopetra e a família Mutillidae. No período da tarde, foi verificada a presença de inseto pertencente a ordem Hemiptera e a família não identificada.

$\mathrm{Na}$ sexta avaliação, 60 dias após o plantio, foi verificada a mortalidade de mais exemplares de ervamate (T2-R3, T2-R6, T2-R7, T3-R1, T3-R3 e T4-R2). Foi verificada ainda a desfolha de cerejeira em T4-R1 e T4-R6 e na erva-mate do T2-R5. No período da tarde, foi verificada a presença de lagarta no exemplar de ervamate, referente à T2-R1.

$\mathrm{Na}$ sétima avaliação, 90 dias após o plantio, foi verificada apenas a presença de formigas no ninho referente à T3-R4, além da mortalidade de mais exemplares de erva-mate (T2-R5 e T3-R1) e a mortalidade de exemplares de aroeira-pimenteira (T2-R7 e T4-R4). Além disso, foi encontrado um exemplar de aroeirapimenteira com a presença de flores (T1-R3).

As manchas foliares verificadas nas espécies ervamate, araçá e pitanga podem ser causadas pelo efeito da temperatura, pois o plantio foi realizado no verão, onde a incidência solar é maior e pode prejudicar as mudas.

O encarquilhamento das folhas de erva-mate pode ter sido causado pela ampola-da-erva-mate (Gyropsylla spegazziniana Leizer) (Hemiptera: Psyllidae), que se alimenta da seiva da planta, deixando os brotos deformados e causando o encarquilhamento das folhas (COSTA et al., 2011).

Durante as avaliações, foram encontrados 16 insetos presentes nos ninhos ou nas mudas. Esses insetos pertencem a cinco ordens diferentes: Coleoptera, Diptera, Hemiptera, Hymenoptera e Orthoptera, e uma ordem não identificada; e a dez famílias, sendo que três não foram identificadas (Tabela 1).

De acordo com a Tabela 1 a ordem Diptera foi a que apresentou a maior quantidade de insetos coletados durante as avaliações (37,50\%), seguida da ordem Orthoptera (25\%), Hymenoptera (18,75\%), Coleoptera (6,25\%) e Hemiptera (6,25\%) (Figura 3).

A principal praga das espécies utilizadas é a Anastrepha fraterculus Wied. (mosca-das-frutas), que tem os frutos das mirtáceas como principais hospedeiros (PEREIRA-RÊGO et al., 2011). Esse inseto pertence a ordem Diptera e a família Tephritidae (BOTTON et al., 2003). 
Tabela 1. Insetos coletados através de análise visual em ninhos de sistemas agroflorestais

\begin{tabular}{|c|c|c|c|}
\hline Ordem & Família & Exemplar & Espécie arbórea \\
\hline Coleoptera & Dasytidae & 1 & erva-mate \\
\hline \multirow[t]{3}{*}{ Diptera } & Culicidae & 2 & erva-mate, pitanga \\
\hline & Tipulidae & 1 & erva-mate \\
\hline & $\mathrm{NI}$ & 3 & erva-mate, guabiroba \\
\hline Hemiptera & $\mathrm{NI}$ & 1 & $*$ \\
\hline \multirow[t]{2}{*}{ Hymenoptera } & Formicidae & 2 & erva-mate, guabiroba** \\
\hline & Mutilidae & 1 & $*$ \\
\hline \multirow[t]{2}{*}{ Orthoptera } & Gryllidae & 2 & $*$, cerejeira ${ }^{* *}$ \\
\hline & Tetrigidae & 2 & *, pitanga \\
\hline $\mathrm{NI}$ & & 1 & erva-mate \\
\hline Total & & 16 & \\
\hline
\end{tabular}

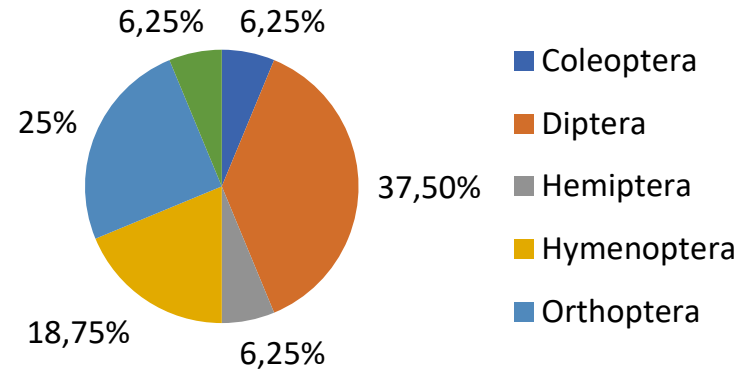

Figura 3. Percentual das ordens de insetos coletados em Sistemas Agroflorestais Multiestrata em São João do Triunfo - PR.

Da erva-mate, as principais pragas consideradas são, Hedypathes betulinus Klug, Coleoptera: Cerambycidae (broca-da-erva-mate); Thelosia camina Schaus, Lepidoptera: Eupterotidae (lagarta-da-erva-mate); Ceroplastes grandis Hempel, Hemiptera: Coccidae (cochonilha-de-cêra); Gyropsylla spegazziniana (Lizer y Trelles), Hemiptera: Psyllidae (ampola-da-erva-mate); Isomerida picticollis Bates., Coleoptera: Cerambycidae (broca-dos-ponteiros-da-erva-mate); Hylesia sp. Lepidoptera: Hemileucidae (lagarta-do-cartucho) e os ácaros (IEDE; MACHADO, 1989; PENTEADO; IEDE, 2010).

Não foi verificada a presença de exemplares dessas famílias nos indivíduos de erva-mate, porém, foi encontrado inseto pertencente à família Dasytidae, não sendo considerado praga principal da espécie, mas requer atenção (IEDE; MACHADO, 1989). Foram encontradas folhas encarquilhadas na erva-mate, porém, não foi encontrado o agente causador do dano o Gyropsylla spegazziniana.

Com base nos dados obtidos, nota-se que a erva-mate apresentou maior porcentagem de ocorrência de insetos
(50\%), seguida pelas espécies guabiroba (25\%), pitanga $(16,67 \%)$ e cerejeira (8,33\%). Porém, não foram considerados os insetos encontrados na área experimental como um todo (quatro exemplares), e os insetos encontrados nos ninhos foram contabilizados apenas na espécie referente ao tratamento (dois exemplares - guabiroba; um exemplar - cerejeira).

Não foi verificada a presença de insetos nos exemplares de aroeira-pimenteira e araçá, mas os danos encontrados nas mesmas podem ser associados aos insetos presentes na área experimental, ou nos ninhos como um todo. Assim a composição com a menor presença de insetos foi relacionada ao Tratamento 1 (araçá, aroeira-pimenteira e erva-mate).

Mostrando-se uma boa composição com relação à incidência de inseto-praga, pois a maior diversidade de espécies faz com que haja diminuição na presença de insetos-praga. Porém há diversidade de insetos presentes, mas em menor quantidade, sendo assim o sistema agroflorestal uma alternativa para diminuição da incidência de insetos-praga.

Com relação à mortalidade, apenas erva-mate e aroeira-pimenteira apresentaram indivíduos mortos. A erva-mate foi a espécie que apresentou maior mortalidade $(37,5 \%$ - 12 indivíduos) e a aroeirapimenteira apenas $6,25 \%$ (dois indivíduos). Isso pode ser atribuído ao ataque dos insetos e as altas temperaturas durante o período avaliado.

Essa mortalidade pode ainda ser atribuída à época do plantio, visto que, para a erva-mate, é indicado o plantio a partir do mês de abril, podendo se estender até setembro (MEDRADO; STURION, 2010). A espécie ainda exige sombreamento durante seu estágio inicial, podendo se esse mais um fator relevante para a grande mortalidade de indivíduos.

Foi realizado para todos os tratamentos (araçá, pitanga, guabiroba e cerejeira) o teste de variância, seguido do teste de Tukey quando necessário, para verificar se houve variação na presença de insetos entre os tratamentos. Por meio desses testes, a uma probabilidade de $5 \%$, foi verificado que os tratamentos não diferem estatisticamente (Tabela 2).

Tabela 2. Análise de variância dos insetos encontrados nos diferentes tratamentos

\begin{tabular}{ccccc}
\hline FV & GL & SQ & QM & F \\
\hline Tratamentos & 3 & 0,84375 & 0,28125 & $1,1887^{\text {ns }}$ \\
Resíduo & $\mathbf{2 8}$ & 6,62500 & 0,23661 & \\
\hline Total & $\mathbf{3 1}$ & $\mathbf{7 , 4 6 8 7 5}$ & & \\
\hline
\end{tabular}

ns = não significativo $(p \geq 0,05)$. 
Os mesmos testes foram realizados para verificar se houve variação da presença de insetos junto à aroeirapimenteira e a erva-mate, os quais também não diferiram estatisticamente (Tabela 3).

Tabela 3. Análise de variância dos insetos encontrados em aroeira-pimenteira e erva-mate

\begin{tabular}{ccccc}
\hline FV & GL & SQ & QM & F \\
\hline \multicolumn{5}{c}{ Aroeira-pimenteira } \\
\hline Tratamentos & 3 & 0,09375 & 0,03125 & $0,2121^{\text {ns }}$ \\
Resíduo & 28 & 412,500 & 0,14732 & \\
\hline Total & 31 & 421,875 \\
\hline \multicolumn{5}{c}{ Erva-mate } \\
\hline Tratamentos & 3 & 2,12500 & 0,70833 & $1,6879^{\text {ns }}$ \\
Resíduo & 28 & 1,17500 & 0,41964 & \\
\hline Total & 31 & 1,38750 \\
\hline
\end{tabular}

ns = não significativo $(p \geq 0,05)$.

Segundo a análise realizada, não houve diferença significativa com relação à presença de insetos nas diferentes composições dos sistemas agroflorestais. Sendo que não foram encontrados insetos-pragas no local. Isso se deve à diversidade do sistema agroflorestal, pois tende a atrair inimigos naturais, como pássaros e morcegos, controlando ou reduzindo a quantidade de insetos (COELHO, 2012).

A diversificação de espécies de plantas tende a reduzir a população de uma praga, por ter menos abundância do seu alimento. Também devido à diversidade encontrada os insetos terão mais dificuldade em localizar suas plantas preferidas, pois estarão dispersas e mascaradas devido à presença de diferentes espécies (AQUINO; ASSIS, 2005).

Com relação aos ninhos, verificou-se que os ninhos mais próximos à mata nativa se encontraram menos danificados por insetos. Quanto à composição dos ninhos, a erva-mate apresentou maior número de indivíduos mortos junto à pitanga. Relacionando os mesmos à incidência de insetos e ao crescimento é indicado as seguintes composições de ninhos: aroeira-pimenteira, erva-mate e araçá; e aroeira-pimenteira, erva-mate e cerejeira.

Dentre os insetos encontrados nos ninhos, apenas formiga cortadeira (Acromyrmex) e coleoptera pertencente à família Dasytidae são considerados insetospragas, porém deve-se realizar o monitoramento e a avaliação dos danos a longo prazo para verificar possíveis danos econômicos ao plantio.

\section{CONCLUSÕES}

Há incidência de insetos em todas as espécies testadas nos ninhos, indicando que deve ser realizado o monitoramento deles e, quando necessário, o controle. Após a análise dos dados e identificação dos insetos não é possível avaliar a ocorrência de dano econômico, necessitando de tempo maior de avaliação. Contudo, os resultados indicam que os insetos encontrados não causam danos às mudas, sendo as espécies indicadas para a utilização em ninhos nos sistemas agroflorestais.

Recomenda-se o plantio em ninhos nos sistemas agroflorestais, visando o aspecto entomológico, pois verifica-se poucos insetos que causam danos às mudas, podendo ainda contribuído no controle natural. Com relação aos ninhos, a melhor composição com relação à incidência de insetos é aroeira-pimenteira, erva-mate e araçá. A erva-mate apresenta a maior incidência de insetos e indivíduos mortos.

\section{REFERÊNCIAS}

ARIAS, H. A. Influencia de la diversidad de especies de plantas em la incidencia de plagas de cultivos en sistemas agroflorestales. Agronomia Colombiana, v. 4, p. 57-62, 1987.

AQUINO, A. M.; ASSIS, R. L Agroecologia: princípios e técnicas para uma agricultura orgânica sustentável. Brasília: Embrapa Informação Tecnológica, 2005. 517 p.

BOtTON, M; ARIOLI, C. J.; BAVARESCO, A.; SCOZ, P.L. Principais Pragas. In: PROTAS, J. F. S.; MADAIL, J. C. M. Sistemas de produção de pêssego de mesa na região da Serra Gaúcha. Embrapa Uva e Vinho: Sistemas de Produção, v. 3, 2003. Disponível em: <http://sistemasdeproducao.cnptia.embrapa.br/ FontesHTML/Pessego/PessegodeMesaRegiaoSerraGaucha/praga s.htm>. Acesso em: 03/05/2017.

COELHO, G. C. Sistemas agroflorestais. São Carlos: RiMa, 2012. $184 \mathrm{p}$.

EMBRAPA FLORESTAS. Classificação climática - clima Cfb. 2017. Disponível em: <http://www.cnpf.embrapa.br/pesquisa/efb/ clima.htm>. Acesso em: 10/04/2017.

FAZOLIN, M.; SILVA, W. S. Comportamento de pragas de importância econômica em culturas anuais, componentes de sistemas agroflorestais. Rio Branco: EMBRAPA, 1996. 26 p. (Boletim de Pesquisa, 14).

FUJIHARA. R. T.; FORTI, L. C.; BALDIN, E. L. L.; ALMEIDA, M.C. de Insetos de importância econômica: guia ilustrado para identificação de famílias. 21. ed. Botucatu: FEPAF, 2011. 391 p.

IAPAR. Classificação climática. 2017. Disponível em: $<$ http://www.iapar.br/modules/conteudo/conteudo.php?conte $\underline{\mathrm{udo}=863}>$. Acesso em: 10/04/2017. 
IEDE, E. T.; MACHADO, D. C. Pragas da erva-mate (Ilex paraguariensis St Hill.) e seu controle. Boletim de Pesquisa Florestal, n. 18/19, p. 51-60, 1989.

IPARDES - Instituto Paranaense de Desenvolvimento Econômico e Social. Diagnóstico socioeconômico do território Paraná Centro - estado do Paraná. Curitiba, 2007. 138 p.

MARTINOSKI, L.; VOGEL, G. F.; MARTINS, P. J. Sistemas Agroflorestais na Recuperação de Matas Ciliares. ANAP Brasil, Revista Científica, v. 6, n. 7, p. 195-212, 2013.

MEDRADO, M. J. S.; STURION, J. A. Cultivo da erva-mate implantação. 2. ed. Embrapa Florestas: Sistemas de Produção, v. 1, 2010. Disponível em: <http://sistemasdeproducao.cnptia. embrapa.br/FontesHTML/Erva-mate/CultivodaErvaMate 2ed/ Implantacao.htm>. Acesso em: 03/05/2017.

NARDELE, M.; CONDE, I. Apostila sistemas agroflorestais. Universidade Federal Rural do Rio de Janeiro. Disponível em: $<$ http://r1.ufrri.br/cfar/d/download/Apostila\%20Agroflorestas.p df>. Acesso em: 03/03/2017.

PENTEADO, S.R.C.; IEDE, E.T. Cultivo da erva-mate - pragas. 2. ed. Embrapa Florestas: Sistemas de Produção, v. 1, 2010. Disponível em Disponível em: <http://sistemasdeproducao. cnptia.embrapa.br/FontesHTML/Erva-mate/CultivodaErvaMate 2ed/Pragas.htm>. Acesso em: 03/05/ 2017.

PEREIRA-RÊGO, D. R. G.; JAHNKE, S. M.; REDAELLI, L. R.; SCHAFFER, N. Morfometria de Anastrepha fraterculus (Wied) (Diptera:Tephritidae) Relacionada a Hospedeiros Nativos, Myrtaceae. Arquivo do Instituto Biológico, v. 78, n. 1, p. 37-43, 2011.

REZENDE, M. Q.; PEREZ, A. L.; JANSSEN, A.; VENZON, M. 11781 Uso do ingá (Inga subnuda) em cafeeiros sob sistemas agroflorestais pode diminuir os danos causados pelas principais pragas do café? Cadernos de Agroecologia, v. 6, n. 2, p. 1-5, 2011. Disponível em: <http://www.aba-agroecologia.org.br/ revistas/index.php/cad/article/view/11781/8119>. Acesso em $30 / 03 / 2017$.

WATANABE, M. A.; ABREU, L. S. 025 - Transição agroecológica para um uso mais sustentável do solo em Ouro Preto do Oeste, RO. Cadernos de Agroecologia, v. 5, n. 1, 2010. Disponível em :<http://www.abaagroecologia.org.br/ojs2/index.php/cad/articl e/download/10135/6824>. Acesso em: 29/03/2017. 